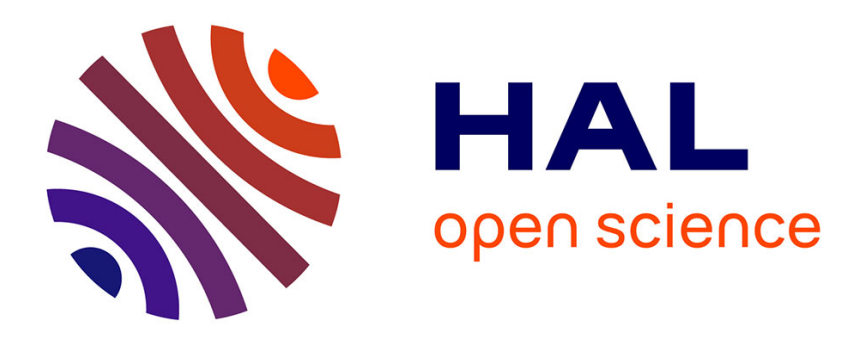

\title{
Grain boundary structure and mechanical properties
}

\author{
V. Randle, B. Ralph
}

\section{To cite this version:}

V. Randle, B. Ralph. Grain boundary structure and mechanical properties. Revue de Physique Appliquée, 1988, 23 (4), pp.501-512. 10.1051/rphysap:01988002304050100 . jpa-00245797

\section{HAL Id: jpa-00245797 https://hal.science/jpa-00245797}

Submitted on 1 Jan 1988

HAL is a multi-disciplinary open access archive for the deposit and dissemination of scientific research documents, whether they are published or not. The documents may come from teaching and research institutions in France or abroad, or from public or private research centers.
L'archive ouverte pluridisciplinaire HAL, est destinée au dépôt et à la diffusion de documents scientifiques de niveau recherche, publiés ou non, émanant des établissements d'enseignement et de recherche français ou étrangers, des laboratoires publics ou privés. 


\title{
Grain boundary structure and mechanical properties
}

\author{
V. Randle and B. Ralph * \\ Department of Materials Technology, Brunel, The University of West London, Uxbridge, \\ Middlesex UB8 3PH, G.B.
}

(Reçu le 15 juin 1987, accepté le 19 novembre 1987)

\begin{abstract}
Résumé.- Une description détaillée de la structure des joints de grains est faite, en se concentrant sur les modèles qui peuvent être vérifiés sur la base des résultats expérimentaux dans les polycristaux. Une revue est également faite des études expérimentales récentes consacrées aux aspects cristallographiques en liaison avec la texture de désorientation des grains. On montre que le lien est fort entre les propriétés et les caractères géométriques des joints de grains. Ce lien est particulièrement important dans le cas des propriétés mécaniques.
\end{abstract}

Abstract.- A comprehensive review of grain boundary structure is given concentrating on models which can be tested on the basis of experimental results from polycrystals. A survey is also given of recent experimental studies, centered upon the crystallographic aspects in terms of the grain misorientation texture. It is shown that there is a strong connection between properties and the geometrical character of a grain boundary. This connection is particularly important in determining mechanical properties.

\section{Introduction}

The strategy of approach to the relationship between grain boundary structure and properties, with particular reference to mechanical properties, begins by reviewing the models which define the geometrical parameters of the boundary. Secondly, the present understanding of how boundary geometry influences mechanical and other properties is outlined. The next section iliustrates some of these structure/property relationships by reference to examples from the authors' recent experimental work. The emphasis is then turned toward the mechanical behaviour of polycrystals in the light of structural influences. Also, the philosophy of "grain boundary engineering" is discussed as a goal, which can be achieved through developing and extending knowledge of boundary structure/property effects.

\section{Grain boundary structure}

In order to describe the geometrical relationship between any two arains, $7 t$ is necessary to define five main degrees of freedom. Two degrees of freedom define the axis of misorientation, $l$, and one is required to specify the angle of misorientation, $\theta$. If the first grain is notionaliy rotated through $\theta$ about $l$, by definition the orientation of the second grain is achieved (figure 1). The remaining two degrees of freedom are required to define the orientation of the boundardy plane. Any experimental analysis of grain boundary structure is based on measurement of at least the first three of these parameters.

Once the axis/angle pair, $l / \theta$ has been determined, the first division of grain boundary structure is apparent, that is, whether a boundary falis into the nigh angle or low angle $\left(\Theta<10-15^{\circ}\right)$ class. The structure of low angle boundaries is characterised by arrays of lattice dislocations, termed primary intrinsic grain boundary dislocations, which totaliy account for the misorientation and the relaxed structure [1]. This type of boundary configuration is we 17 understood. At misorientations between 10-15\%, the overlap between neighbouring dislocation cores means that the individual identity of primary dislocations is lost and the boundary can no longer be characterised in

* Now at Department of Materials Technology, Brunel University of West London, Uxbridge, U.K. 
such simple terms. The largest value of $\Theta$ for which primary dislocations have been recorded in a boundary is $15^{\circ}[1]$. For Targer misorientations $\theta>10-15^{\circ}$, the traditional view is that many boundaries are randomly oriented with respect to their neighbours, but some are characterised by non-random geometrical relationships. One of the first expressions of this type of structured boundary is due to Mott [2], who developed the transition lattice model of Hargreaves and $\mathrm{Hil} 7$ to describe boundaries as regions of good fit interspersed with regions of poor fit. From this simple approach many structural theories subsequentiy evolved; they a 71 feature the common theme that, for a proportion of boundaries, there is a repeating arrangement of the adjoining atoms at the boundary. The concept of periodicity has been quantified by several approaches, but only the coincident site lattice (CSL) [3] and coincident axial direction/planar matching (CAD/PM) models $[4,5]$ wi77 be described in detail here since they are the most easily applicable models to large statistical studies of many boundaries in polycrystals. For certain combinations of $l / \theta$, some lattice points of grain will coincide with those of grain 1 to give a superstructure of coinciding sites[3]. Figure 2 snows a $36.9^{\circ}$ rotation around $(100$ ) which causes 1 in 5 lattice points from grains 1 and 2 to coincide; this is referred to as a $\Sigma=5$ CSL. At the boundary plane, the perodicity is on average $51 \% 3$ since the volume of the CSL cel1 varies as $\Sigma[\epsilon]$. The ordered arrangement of atoms in a CSL boundary often allows much closer packing in the grain boundary plane than for the disordered case, particulariy where rigid body translations permit the boundary to relax to a better fit [7].

A CSL exists only for precise values of $\ell / \theta$. However, the CSL structure can be conserved by arrays of dislocations whitch maintain the 3-dimensional superstructure. Such dislocations are termed secondary intrinstc grain boundary dislocations since they take up the angular deviation from an exact high derisity (low $\Sigma$ ) CSL in a mariner precisely analagous to the misorientation across a low arigle $(\Sigma=1)$ boundary betng maintatned by primary gratn boundary dislocations. There is much TEM evidence for the extstence of near CSL boundaries in the form of arrays of gratr boundary dislocations (e.g 6 ). Not a 11 the evidence is the result of oriented bicrystal studies: structured boundartes are known to a 150 extst in polycrystals (e.g. 8,9 ).

If high enough values of $\Sigma$ are allowed. any boundary may be described fn terms of a CSL, although the phystcal stgntflcance of very long pertod boundartes is probably sma17. For values of $\Sigma$ greater than about 49. It is more corventent to constaer matchtrig th one dimenston only rather than three. because at this stage the three
Burgers vectors of grain boundary dislocations. $b_{1}, b_{z}, b_{0}$, have become extremely arisotropic with the largest Burgers vector, $b_{3}$, approaching the dimensions of the interplanar spacing while $b_{2}$ and $b=$ become extremely sma71[10]. This type of one dimensiona? matching is described by the PM theory [5], or if considered from the standpoint of the deviation from parallelism of the plane stack normals in the direction of $b_{3}$, the CAD theory[4]. Support for the PM theory comes from the observation of dislocations in boundaries which are several degrees away from the nearest low index CSL (e.g.11) and, as will be discussed in a later section, the PM/CAD approach is particularly suitable for application to textured materials (e.g. 12).

Other approaches to grain boundary geometry have contributed to the present understanding of boundary structure. Boliman's 'O' lattice model enables a completely quantitative description of any boundary to be formulated. It is a continuous function of grain misorientation and so CSL's emerge as a speciat case where the 'O' points regions of best match - coinctde with lattice points[13]. Formulation of the DSC lattice (a sublattice of the ' $O$ ' lattice) allows possible Burgers vectors of grain boundary dislocations to be predicted. The structural unit mode1 [14] a 150 arose from the fundamental premise of fit/misfit regions in the boundary, but adopts the view that poor fit regions are equivalent to the insertion of smal1 groups of atoms, which give rise to ledges at the boundary. Those ideas later evolved into the "random close packed units" model which constders that vartous polynedra of atom groups provide the basic butlding blocks of boundary structure [15]. Fina $71 \%$, the current knowledge of boundary structure could not have progressed to its present level without the recent atomistic studies of boundary geometry made possible by the advance of high speed computers (e.g. 16).

\subsection{Proportions of special boundaries in a samp $7 e$}

In order to calculate the proportion of special boundaries that could result from a random distribution of misortentations, a knowledge of the maxtmum deviation from the exact CSL, $V_{m z}$ (or CAD $V_{m i}$ ) which can be accommodated by grain boundary dislocations is required. Most workers choose the CSL Timit as [3]

$$
v_{m \geq}=v_{0} \Sigma^{-\frac{1}{2}}
$$

where vo is the arigular 1 imit for $\Sigma=1$, i.e $15^{\circ}$. Similariy the CAD limit is defined as [4]

$$
V_{m 1}=(a / b) \pi^{-\frac{1}{2}}
$$

where $a$ is the lattice parameter, $b$ is the 


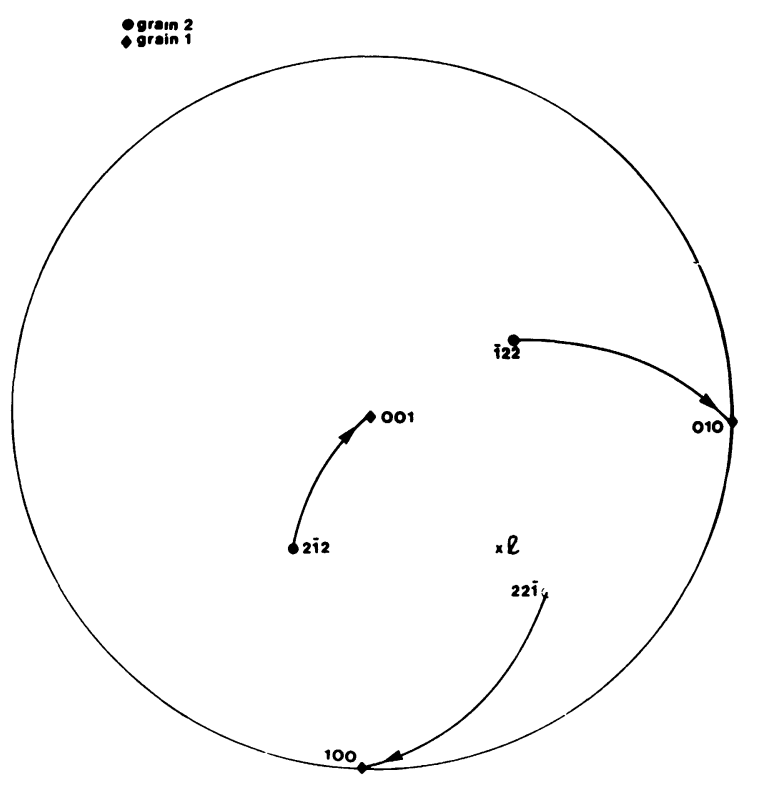

Figure 1. Stereographic representation of a twin-related bicrystal (illustrating the definition of $l / \theta$ (see text)). A clockwise rotation of $60^{\circ}(\theta)$ about the common [111]

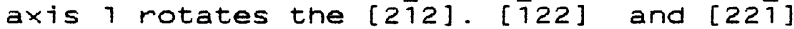
directions in crystal 2 on to the crystal axis, $\langle 100\rangle$ of crysta 11 (Courtesy

J.Mat.Sci. reference [23]).

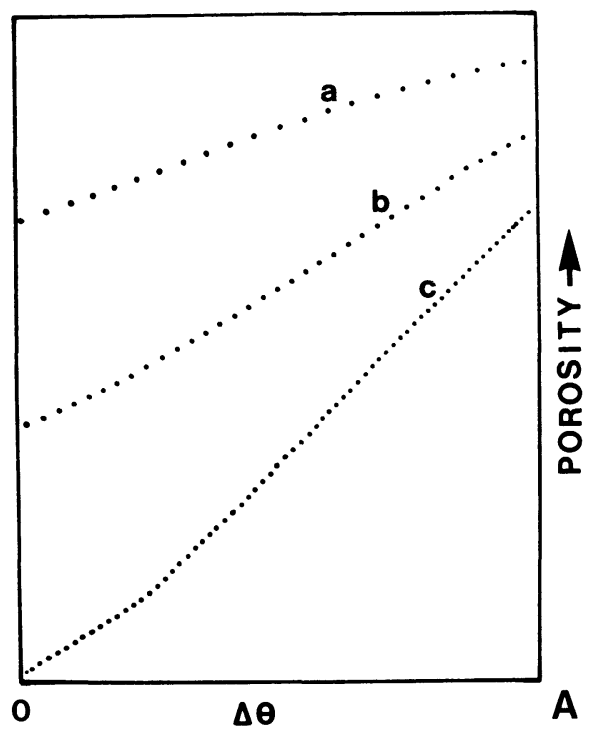

Ftgure 3. Schematic plots of (A) porostty functions (B) concentration furiction of segregant and (C), the sum of $A$ and $B$. boundary mobility as a function of misorientation, $\Delta \boxminus, a, b$ and $c$ refer respectively to random, medium denstty and high denstty CSL bouridartes (After Gordon and vandermeer, [21].

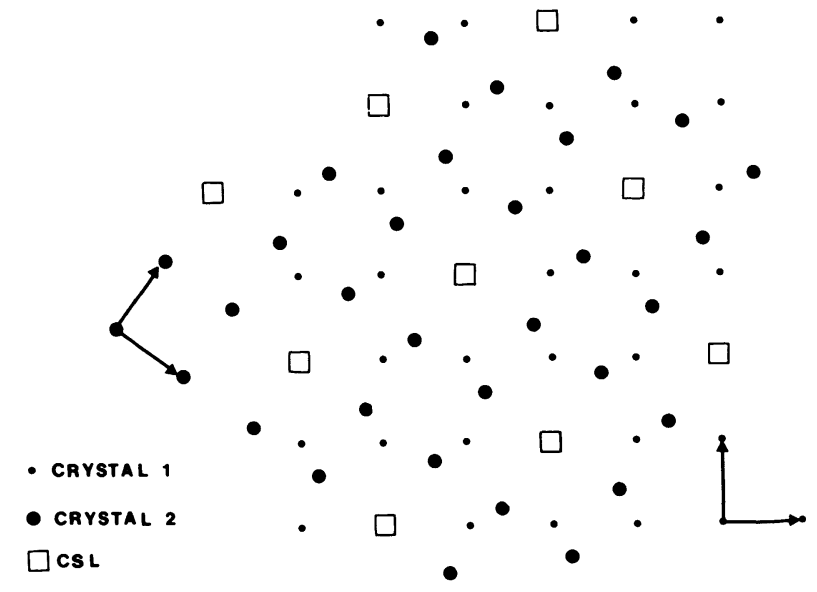

Figure 2. Illustration of the geometrical relationships giving rise to a $\Sigma=5$ coincidence site lattice (CSL).
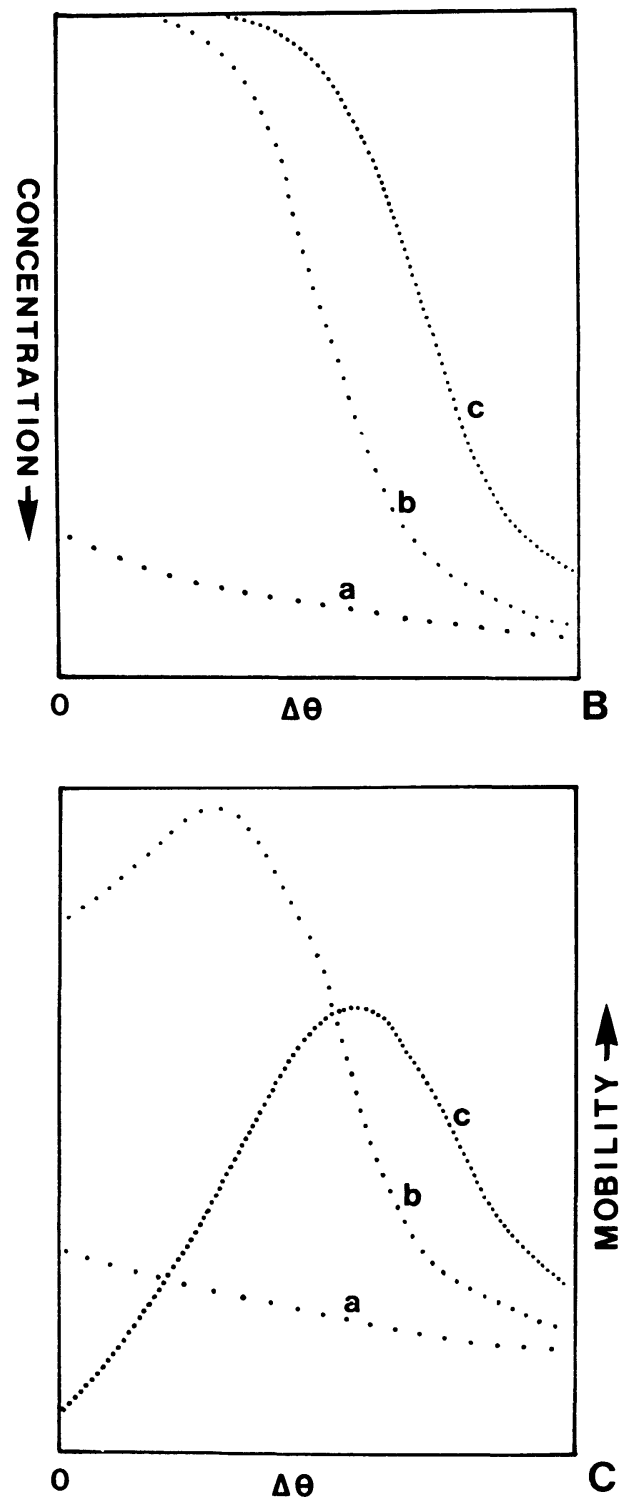
Burgers vector and $\pi=n \geq+k=+7 \geq$ for axis of misorieritation nkl. These limits are not absolute and intended as guidelines only, particularly since the limits to experimental resolution prevent the detection of very closely spaced dislocation arrays. It is suggested by some workers that, as further dislocation hierarchies are "pressed into service", larger deviations than those suggested by equation (1) may be represented by a dislocation model[17]. In fact, it is quite possible that most if not ali grain boundaries may be located in an "energy valley"[4]. It has been shown that if a completely random distribution of rotations is generated, for cubic materials $9 \%$ of these rotations should be special boundaries with $3<\Sigma<25$ and $2 \%$ low angle types [4]. For the CAD case, it is estimated that about $50 \%$ of a 11 boundaries should have axes lying within an angular range within $V_{m} 1$ of the normals to $\{200\}$, $\{220\}$ and $\{111\}$ plane stacks. Any deviations from a random distribution of grains would be expected to change these proportions.

\subsection{Boundary structure/segregation effects}

The segregation to grain boundaries of elements which have limited solid solubility in the host matrix is frequentiy accompanied by changes in the boundary's energy and mobility. Ever materials which are nominaliy pure may show orders of magnitude change in boundary migration rate due to the presence of less than $0.003 \%$ solute[18]. A few segregants in specific systems such as $B$ in $N i$ are "cohesive enhancers" but the majority of segregating spectes such as $S$ and $P$ in $F e$ are the cause of embrittlement in grain boundaries[19]. However, from a number of investigations involving both bicrystals and polycrystals (e.g. 20) it is now clear that boundary segregation is extremely orientation dependent and that special boundaries (CSL and low angle) are far less susceptible to segregation than are random boundaries. The key to this behaviour is that, since special boundaries are relatively close packed compared to random geometries, there is less free volume associated with spectal boundartes and consequentiy less avaliable space for segregating species. The relationship between boundary porosity, mobility and local segregant concentration has been explored by Gordon and vandermeer, who postulate that boundary mobtitty is a sensitive function of both porosity and segregation[21]. If curves schematicaliy representing the relattonship between both boundary porostty and local solute concentration with misorientation from exact matching are summed, the boundary's moblitty may be predicted[21]. If random, high density CSLS (e.g $\Sigma=3$ ) and lower denstty CSLS are treated separately. It becomes clear from the schematic plot of moblitty versus orientation function in figure 3 that the mobility of CSL boundaries is nigher thar that for random bouridaries for a 11 values of $\theta$ except nigh density CSLs at or very near exact coincidence. The maximum mobility occurs for medium coincidence boundaries, which deviate from precise coincidence by a few degrees. High density CSLS at exact coincidence (the coherent twin is a well known example) tend to be almost immobile because the atomic packing is so close as to resemble the lattice and consequently the activation energy for migration is less than for a disordered boundary, where ths associated free volume contributes to a low activation energy.

Where a system is supersaturated with respect to grain boundary solutes, it is therefore likely that random boundaries wi11 predominate over CSLS. These concepts which relate segregration effects to boundary structure can be exterided to include the situation where supersaturation at the bouridary is relieved by precipitation[22]. After precipitation, less free volume is taken up at the boundary by solute, and therefore a ntgh proportion of spectal boundaries should be favoured than for the boundary-supersaturated regime.

The models of boundary structure outitred in the prevtous sections, and the way in which they relate to certain boundary properties, wi 71 now be discussed in the light of recent experimental results by the present authors.

3. Evidence supporting theories of grain boundary structure/property relationships

The first step towaras relating experimentajiy acquired knowledge of boundary structure to boundary properties and behavtour is the collection of a large enough data base to be able to araw statisticaliy based conclusions concerning structure/property control. The present authors have used expertmental techntques based efther upon covergent beam electron diffraction CBED in a TEM[23], or electron back scattering EBS in an SEM[24] to collect data. The relative mertts of both approaches are 1 isted in table 1 . In the remalnder of this section, some aspects of these trivestlgations w171 be summartsed.

Although the $C A D$ model can be treated with the same formalism as the CSL model, the former has not prevtousiy been applied to the anajysts of boundary structure. The present authors have collated axts/angle patrs from matertals of tncreasing complextty - pure copper, a two phase a $710 \mathrm{y}$ of $A T$ and $A T=03$, a single phase austenitic stainiess steel, a ferritic statniess steel and a complex ntckel based superalioy - and categortsed them according to the nearest $C A D$ axts[25]. A compartson is then posstble between the theorettca 1 and observed 
proportions (table 2). The distribution of axes varies from the preatcted frequencies, which the authors describe as "grain misorientations texture", GMT. The existence of these textures could be either the cause or the result of grain texture[6]. In other words either a preferred orientation may exist in the material which directiy controls the GMT or misorientations are selected by differentials in migration rates, energies or chemistry. The preferred orientation case applies to the $\mathrm{A} 7 / \mathrm{A} 7 \geq \mathrm{O}$ a a lloy which has been drawn to a wire and contains a high proportion of $\langle 200\rangle$ CAD's (table 2 ). The other two subgroups in table 2 which exceed the theoretical frequency - $\langle 111\rangle$ of the austentic stainiess steel and $\langle 200\rangle$ of the ferritic stainiess stee 1 are not strongly textured. where a material is weakly or multi-textured, the investigations which have been conducted so far indicate that the effect on the GMT is very complex. For example, figure 4 iliustrates a large secondary recrystalitised grain in a complex superalioy, the distribution of grain normals of the large grain and surrounding smal1 grains, the GMT of boundaries between small grains, and the GMT of boundartes between the large grain and surrounding smali gratns. On such GMT diagrams as figure $4 c$ and $d$ it is only possible to represent and not $\ell / \theta$, but special combinations of $\ell / \theta$, i.e, CSLS, are indicated. It is evident that the grain growth process has changed the GMT from CSL's having near (220) (sma11/smal1 grain boundaries) to CSLS with near $\langle 171\rangle$ ( large/smal grain boundaries). Since the orientation of the large grain is not differentiated from the surrounding smal1 grains, as illustrated by the distribution of grain normals in figures 4b, in this case the GMT is not the result of preferred orientation.

The theories concerning effects of segregation on grain misorientations which are outlined in the previous section, are further supported by results from a ntckel-based superalloy, Nimonic PE16, after various heat treatment conditions[8]. The mechantcal properties of this material are dependent upon precipitation of $M_{23} C_{e}$ (based on $\mathrm{Cr}_{23} \mathrm{C}_{6}$ ) and $r^{\prime}$, (based on Nia $(T i, A T)$ ). When the alloy is unaged with respect to both these phases, considerable solute supersaturation results.

Table 3 shows the proportions of CSL'S present (a) in the supersaturated state (b) after an ageing treatment has allowed both $\mathrm{CrzaC}_{6}$ and $\mathrm{Nia}(\mathrm{T} T, \mathrm{~A} T)$ to precipitate thus removing a large proportion of segregant, (c) following a $1000 \mathrm{~h}$ anneal which permits considerable coarsening, and (d) following re-solution of $\gamma^{\prime}$ coarsened during $(c)$. Over three hundred boundaries were sampled altogether. There is a clear trend for a progressive increase in the proportion of CSL boundaries and decrease in the preference for random boundaries as precipitaion increases. and boundary segregation decreases. When the overaged specimen is reannealed and quenched to to retain the solute supersaturation caused by solutionisation of the $r^{\prime}$-forming elements, there is an accompanying return to a preference for random boundaries. For a 11 of the neat treatment conditions the CSLs, while within the special boundary criterion given in equation (1), are mostiv $>0.5 \quad V / V_{m z}$ where $V$ is the measured angular deviation of a sampled boundary from an exact CSL. The implication is that these boundaries, which are a few degrees removed from exact CSLs, are more mobile than the random boundaries in the sample population, and that the former have been selected during growth on a structural basis. The large proportion of CSL's after prolonged ageing, and particularly the increase in nearer-idea 7 CSLs for this subgroup from $5 \%$ to $16 \%$, (table 3 ) is only partially justified on the grounds of reduced segregation, since once precipitate growth is completed and true coarsening begins, the proportion of segregant at boundaries wi17 be stablifised[26]. The dominant mechanism for the increased incidence of CSLs in this case is considered to be boundary sliding and is described in a later section.

The relationship between the incidence of CSL boundaries and intergranular precipitation is currentiy being further explored in a 310 stainless steel with Mzace precipitation at grain boundaries. The EBS technique is being employed to collect crystallographic data from many boundaries. Figure $5 a$ shows the variations in precipitate denstty over a typical region, and a 7 so indicates which of these boundaries are low angle, random or CSL (those boundaries which are obviousiy twins were omitted from the sample). The low angle and CSL boundaries commoniy show low or medium density of precipitates and the random boundaries are characterised by medium or high density preciptation. For the whole sample population, on $1 y 14 \%$ of boundaries do not fit these categories (Table 4). Furthermore, the percentage of CSL's before precipitation of Mzacs have increased from $26.5 \%$ to an after preciptation value of $34 \%$, which is consistent with the previous results from the superalloy. There are indications on Figure $5 a$ that the boundary plane orientation also is significant in the control of the precipitate density, and investigation of this parameter and its infiuence on precipitate density is planned.

\section{Mechanical Properties and the Influence of Grain Boundary Structure.}

Grain boundaries have a major effect on most of the physical and chemical properties of materials. Nowhere is this 


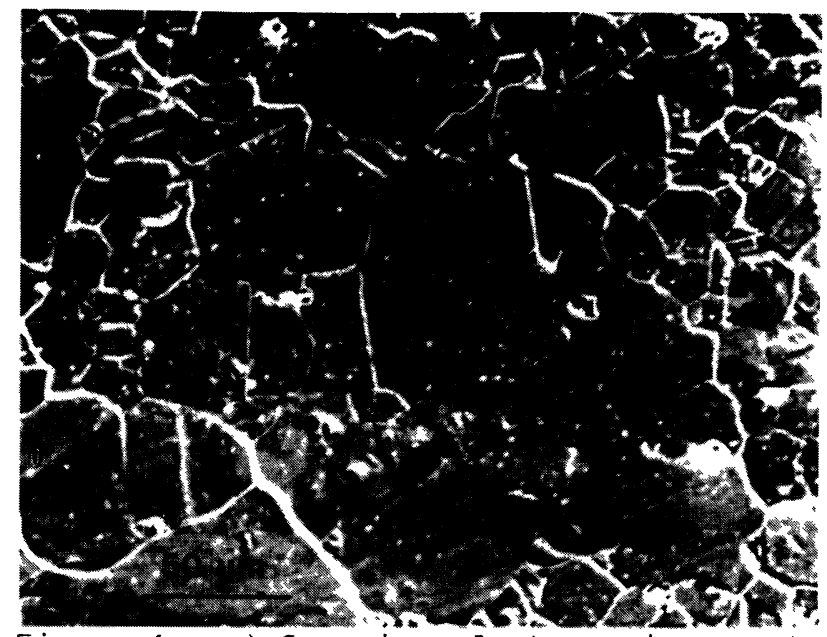

Figure 4 . a) Scanning electron micrographi from Nimonic PEl6 specimen showing the coexistence of large and small grains due to anomalous grain growth.

b) Stereographic unit triargle showing the orientation of the grain normals for a large grain $(x)$ and the surrounding small grains (.).

c) Grain misorientation texture (GMT) Dlot of the small grairs in figure 4a) with the larger symbol referring to CSL situations.

d) GMT as c) but for the boundaries between the large grain and surrounding small grains in figure $4 a$ ).

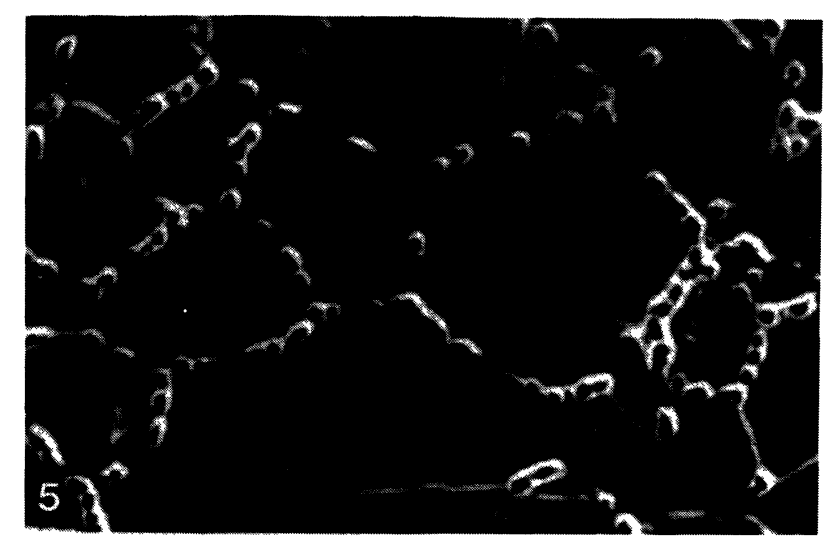

Figure 5 scanning electron micrograph from sample of type 310 austenitic stainless steel showing variations in the density of Mzacs prectpitates at boundaries. Boundaries with special geometries are marked $S$ whilst those of random character are marked $\mathrm{P}$. b

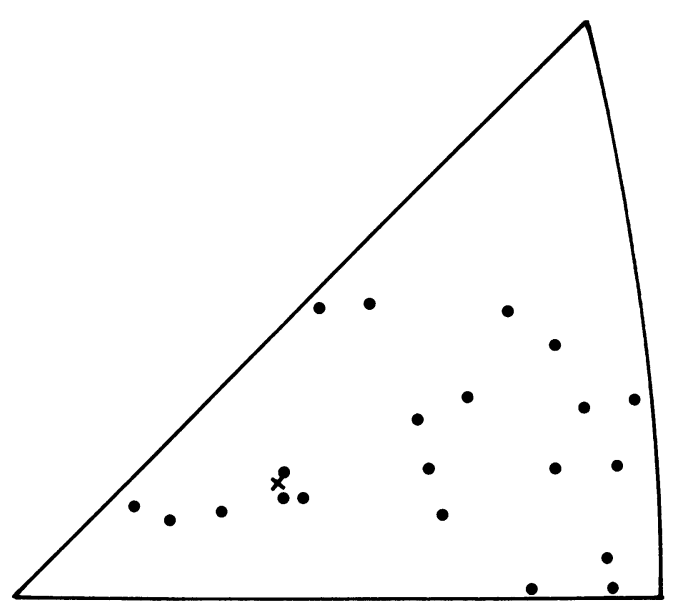

C
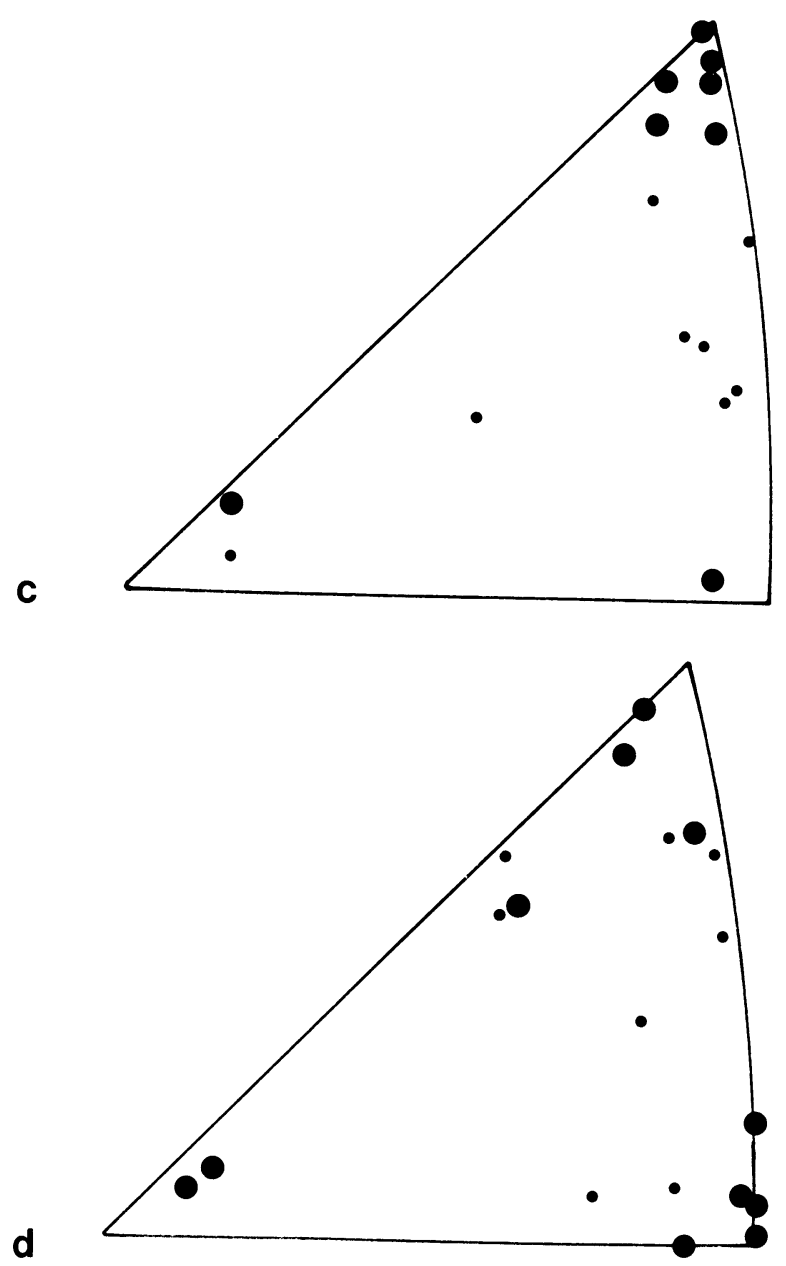
TABLE 1

Comparison of the EBS/SEM method of grain boundary

structura 1

analysis (24) with the CBED/TEM method (23).

EBS

CBED

Accuracy for measurement of $l / \theta \overline{1-2}$ Accuracy for measurement of $\mathrm{l} / \mathrm{O} 0.5^{\circ}$

Data analysis on-line and semi-automatic, therefore very rapid.

Data handing under operator control from diffraction patterns therefore slower.

Many hundreds of grain boundaries available in a single sample.

Typical7y 20-30 boundaries available in a in a single foit.

The grain sizé distribution can be

No grain size specific information.

analysed in terms of grain micro-

texture and related to the GMT.

Information available restricted to that pertaining to grain orientations.

Grain boundary planes, dislocation characters and atomic level composition profiles can be determined.

TABLE 2

Proportions of CAD boundaries \% in five different materials.

\begin{tabular}{|c|c|c|c|c|}
\hline \multirow[t]{2}{*}{ Materia 7} & $\langle 111\rangle$ & $\langle 200\rangle$ & $\langle 220\rangle$ & tota 7 \\
\hline & $(28)^{*}$ & $(12)^{*}$ & $(7 E)^{*}$ & $(73)^{*}$ \\
\hline $\mathrm{Cu}$ & 24 & 2 & 15 & 63 \\
\hline $\begin{array}{c}\text { Austenitic } \\
\text { stee } 7\end{array}$ & 33 & 7 & 9 & 70 \\
\hline$A\rceil / A\urcorner=03$ & 5 & 24 & 9 & 76 \\
\hline Ferritic stee & 12 & 12 & 20 & 70 \\
\hline Nimonte PE16 & 23 & 7 & 12 & 63 \\
\hline
\end{tabular}

* Theoretical7y derived CAD proportions (\%)

\section{TABLE 3}

Proportions of CSL's (\%) in Nimonic PE 16 as a function of ageing heat treatments. Both the special boundary criterion from equation (1) and and angular range equa 7 to half this oriterion, are used to classify the boundaries.

\begin{tabular}{|c|c|c|c|c|}
\hline Heat treatment & $V / V_{m} \mathbf{z}$ & $<1$ & $V / V_{m z}$ & $<0.5$ \\
\hline unaged & & 10 & & 5 \\
\hline aged & & 21 & & 5 \\
\hline overaged & & 40 & & 16 \\
\hline $\begin{array}{l}\text { solution treated } \\
\text { after overageing. }\end{array}$ & & 21 & & 5 \\
\hline
\end{tabular}

TABLE 4

Relationship between grain boundary precipitation of Mazcs and boundary' "spectalness" in 310 staintess steel (see also figure 5 ).

Number of boundaries
$\%$ special boundaries (near CSL $3<\Sigma<43$ or low angle)
\% special boundaries naving $L-M$ precipitation
$\%$ random boundaries naving $\mathrm{M}-\mathrm{H}$ precipitation 
more in evidence than in the response of a polycrystal to stress. The interest then in gratn boundary/mechanical property interrelations spreads from the microscopic to the macroscopic; although it is the former which most concerns us here. The more macroscopic influence is best expressed in terms of equations of the Hal1-Peton type which demonstrate an increase in strength and toughness with decrease in grain size. At the simplest level the strength improvement is attributed to the ability of a grain boundary to limit the motion of dislocations on STIP planes by acting as a barrier or obstacle. In reality, this gives a simplistic picture of the interaction between dislocations and grain boundaries which needs considerable refinement (see below).

The influence of grain boundaries on the fracture mechanism and hence toughness is again extremely complex; only now are the type of grain boundary structural ideas referred to in previous sections beginning to be incorporated into models of the fracture of polycrystals. Here considering the ductile/brittle behaviour involves first looking at interactions between particular grain boundaries having specific structures and any solute impurities which may differentialiy segregate to these boundaries depending on their structure. This may then create an easy fracture path along those boundaries where the separation energy, which incorporates the grain boundary energy in the presence of these solutes, is low. other factors come into this approach which have to consider other fracture paths through the grains and the local plastio work, if any, associated with the fracture process.

In general then, for combinations of nigh strength and toughness with good fatigue resistance, a fine grain structure is known to be optimum. It may wel1 be possible to improve these properties stil1 further by controliing the relative proportion of special (and therefore low segregation, low energy) boundaries (e.g. 201. This takes the subject of texture control (or tailoring) of polycrystals a step further in suggesting that it is not just the overait texture (or the orientation distribution function) which is important but that the rocal texture, GMT, (or grain boundary parameters) need to be controlied to achieve further improvements to properties.

The "design" of materials for operation under load at high temperatures brings into consideration different properties of grain boundaries. Here, under creep conditions we are mainiy concerned with the ability of the grain boundary to resist siding and to avoid the accretion of volds from vacancy condensation. At the simplest level we can minimise or remove these effects by going to specific grain geometries (for instance in directionalyy solidified solids with the grain boundaries paraliel to the stress axis) or by using single crystals. An alternative approach is to "design" the microstructure in the grain boundary regions; for instance by the incorporation of grain boundary precipitates which help to limit sliding. In the future we might nope to modify the microtexture, GMT, so as to maximise the percentage of grain boundaries within the polycrystal which have low sliding and vacancy capture characteristics.

Whilst not directly within the remit of this survey it is perhaps worthwhile stressing that a grain boundary not only has its own geometrical structure but is usual1y, in a practical alloy, associated with its own local microstructure. In genera 1, a grain boundary represents a site where phase transformations are favoured and this in turn frequently leads to a region near to the grain boundary where there is some depletion in phase transformation products (e.g. prectpttate free zone formation). This modified pattern in the microstructures at and near to the grain boundary may lead to very substantial changes in properties. It should be appreciated that this "grain boundary microstructure" is another manifestation of the grain boundary structure which may then have an even more dominant effect on the properties of a polycrvstalitine sample of a commercial a $170 \mathrm{Y}$.

Many of the ideas expressed above are beginning to be considered within the remit of the materials engineer so that designing for instance for strength includes looking to increase the percentage of spectal boundartes[20]. This design process is at an early stage and is related in a number of papers in these proceedings and in the recent iiterature. In the present paper we limit our discussion to looking at some of the more microscopical/geometrical effects on low temperature (next subsection) and high temperature (following subsection) mechantcal properties.

\section{1 Low Temperature Mechanical Properties}

Grain boundaries contribute to strength and toughness in a manner which is reflected in the overall properties of polycrystals. Further, the strength of single boundaries in bicrystals has been measured and shown to vary with the geometrical parameters which define the grain boundary. As yet, a fult explanation for these hardening effects is not avaitable although many of the contributions which grain boundaries make to the strength of polycrystals is becoming clearer.

It is believed that grain boundaries are the main sources of dislocations in 
polycrystalitine alloys. Further there is extenstve evtdence from analytical electron microscopy of the way grain boundaries act as barriers for dislocation motion creating pile ups. Examples of pile ups at grain boundaries are given in figure 6. Figure 6 a shows an example of a planar array of dislocations crossing a grain and hence transferring stress/strain across the grain. This is typical of the form of behaviour seen in polycrystals of an alloy at low strain, although in this case the dislocations are in pairs due to the presence of a fine dispersion of the ordered intermetalitc precipitate $\left(r^{\prime}\right)$. observations of this type, which are common, give rise to two questions which are strongly interrelated:

a) how do the dislocations which are forced into the grain boundary plane modify the grain boundary structure;

b) how does the process of strain transfer from grain-to-grain occur?

The answer to the second question is of constderably more practical importance since, in the absence of this strain transfer, fracture will occur. Whilst a full model for the strain transfer mechanism has yet to be developed, many of the key elements in such a model are now clear. Thus a single slip system in one grain intersecting a grain boundary wi77, in genera 7 because of geometrical constraints, cause more than one sip system in the netghbouring gratn to be activated. Such considerations lead to a physical interpretation of the number of independent sitp systems needed. At a more "microscopic level" this compatability of operating sip systems may be interpreted in terms of densities of geometrically necessary dislocations [27]. Recent treatments of both the yield and the flow stress have started from this type of approach.

At a stili more microscopto level are observations of individual dislocations reacting with the intrinsic structure of grain boundaries of which figures 60 and 5c are typtcal examples. In both these cases the periodic instrinste structure of the grain boundary is resolved and the perturbation to this structure is apparent when a matrix dislocation enters into it. The processes by which this accommodation of matrix dislocations into the grain boundary structure takes place has been the subject of a number of studies a 7 though only a partial picture, as yet, emerges. There is a 150 a suggestion that this accommodation process is affferent in a spectal boundary (possesstrig a short pertod structure) and a more genemal high angle boundary. In the former case, microscoptc evtience extsts which supports the fdea that the matrix dislocation dissociates in the grain boundary plane to gtve secondary extrinstc grain boundary dislocations with the same Burgers vectors as the intrinsics. The line vectors of these dislocations are initialiy governed by the zone axts of intersection of sitp and boundary planes. Because these extrinsic dislocations perturb the periodic structure they have long range strain fields (and nence give stronger diffraction contrast than periodic intrinsics with the same Burgers vectors), and have a dominant effect on properties. Given combinations of glide and climb of these extrinstes in the grain boundary plane, they may eventualiy accommodate to become part of the periodic intrinstc structure. There is less certainty as to what happens when a dislocation enters a random ntgh angle boundary but again one or more extrinsic grain boundary disiocations are formed although the cores of these may subsequentiy spread so that the dislocations are eliminated.

As deformation proceeds the dislocation substructure builas up from the gratn boundary into the matrix. In many metaliic materials this is seen by the formation of even more regular cells which begin at the grain boundartes and spread back into the grains. Flgure 7 i liustrates this phase of the deformation process in two different metalitc specimens. In general at moderate strain levels (around 0.10 ) the cel1 structure near the grain boundary is smalier than it is in the centre of the gratns reflecting the increased dislocation activity which artses from the additional geometrical1y necessary dislocations due to the requirements of stratn compatability across the grain boundary.

\subsection{Grain boundary sitiding}

Grain boundary sitiding is considered to be stgniffcant at temperatures above 0.4 $T_{m}$, and leads to gratn boundary diffuston - related phenomena such as creep and cavttation. However, where the sliding ts not stress - related, a different siliding phenomenon has been observed. Usua $71 y$, during a post recrystalifsation anneal an a110y system wit1 attempt to lower its energy via a reduction in grain boundary area - 1.e. gratn growth. However. the sttuation arises for Nimonic PETE containing coarsened $\gamma^{\prime}$ that boundary migration is totaliy suppressed by the strong interaction of boundaries with $r^{\prime}$ precipitate population. This strong interaction is a consequence of the maintained cohenency of $r^{\prime}$ during coarsentirg, and ts descrtbed in detait elsewhere[8]. Although the transiational motion of boundaries is restricted, they are stili relatively free to sitide or rotate about their axes. In so dotrig, it is possible for more energetica $77 y$ favourable conflgurations to be achieved and thus, for a pinned microstructure, the lack of grain growth associated energy reduction ctrcumvented. It has been proposed that the large thorease in the 

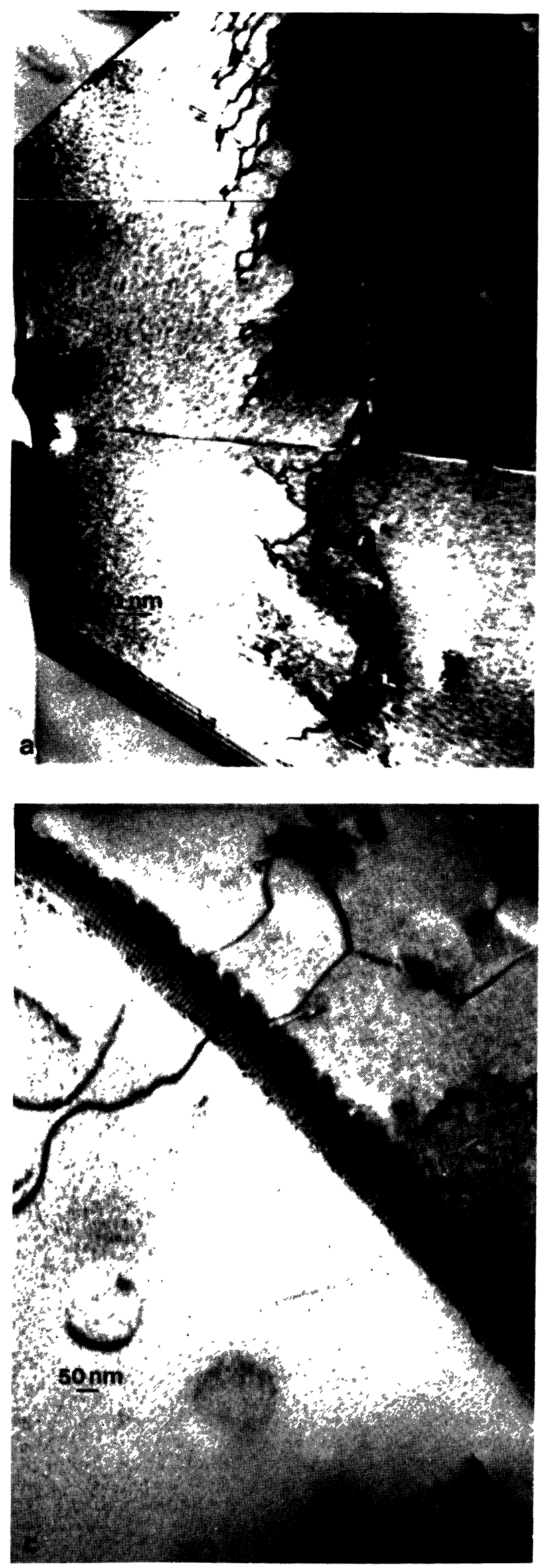

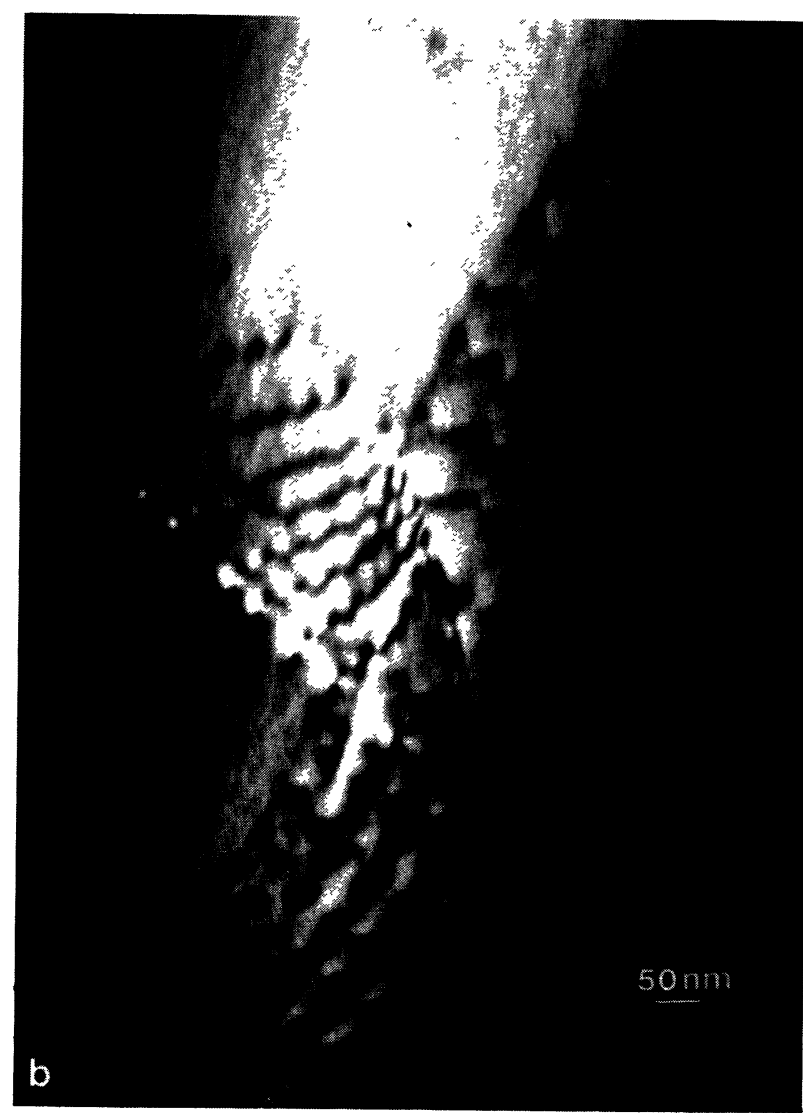

Figure 6. Transmisston electron micrographs of dislocation pite ups in Nimonic PE 16 a) shows a planar array crossing a grain $b)$ shows a pile up entering a near $\Sigma=9$ boundary and $c$ shows an individual dislocation entering a low angle grain boundary. 
proportion of CSL's in PE16 containing strongly pinned, immobile boundaries (table 3 ) is a direct consequence of grain rotations by grain boundary microsifiding [8]. A]though the precise nature of the relationship between $\Sigma$ value and grain boundary energy is complex and still not well understood, [28] it is generally accepted that CSL's with fairly low $\Sigma$ values have lower energies than random boundaries. Hence the nypothesis that CSLS are energetically preferred configurations which boundaries will attempt to approach through siliding, is reasonable.

The sliding mechanism is a we 11 accepted process during creep deformation, and the mechanism of siliding discussed here may be partially analagous to the creep case. Evidence from bicrystals exists for grain boundary rotations towards a CSL by the assimilation of lattice dislocations into the boundary[29]. Additionally, the overali sliding to new boundary orientations necessarily involves cooperative behaviour between boundaries in order to allow grain boundary dislocations to slide from boundary to boundary with suttable Burgers vector adjustments at grain corners. Evidence for the occurrence of adjustments to GMTs which involve complex interactions between grains is not just restricted to the case where boundaries have been strongly pinned for very long times at elevated temperatures, as cited nere for PE16. Other systems, including 310 stainless stee 1 discussed in an earlier section, may show clusters of CSL or near CSL boundaries (e.g. figure 5). The impitcation is that once one or two boundaries which border the same grain have rotated into CSLS (or were already CSLS as a result of grain texture or random selection) it is easier for other local boundaries to also become more ordered.

\section{Concluding remarks}

Essentiaj7y the theme of this article has been to show that a strong link exists between mechanicaj behaviour and grain boundary structure because of the property variations associated with spectal/non special boundary classifications. Generaj7y we can say that a nigh proportion of spectal or ordered boundartes are berieftclal to both strength and ductility, and clearly the ultimate aim is to design materials in such a way as to optimise their gratn boundary properties. Before "gratn boundary engtneering" can be usefully implemented, there is an urgent need to extend our understanding of the factors which Influence grain misorientation distributions. The authors have indicated some of their areas of activity in this tmportant fleid, and thetr phtiosophy ts the statistical study of many boundartes in vartous a $110 y /$ heat treatment combinations. Other approaches iriciude the effect of interactions between lattice and grain boundary dislocations[30], including dislocation "spreading" in the boundary (e.g. 31) intergranular embrittlement (e.g. 30 ) and the concept of structural/phase transformations at the boundary leading to the production of grain boundary phase diagrams. (e.g. 32 )

Acknowledgements The authors are grateful to the S.E.R.C., U.K.A.E.A, C.E.G.B., and S.S.E.B. for financial support and permission to publish. They also acknowledge the courtesy of Dr David Dingley (of Bristol university) in allowing access to and help with the EBS experiments.

\section{References}

1. Ichinose, $H$. and Ishida $Y$., Proc. Int.Conf. on Structure and Properties of Internal Interfaces, Irsee (1984), J. Phys. C4 (1985) 39.

2. McLean, D., Gratn Boundartes in Meta7s. Oxford, (1957).

3. Brandon, D.G., Acta Met. 14 (1966) 1479 .

4. Warrington, D.H. and Boon M., Acta Met. 23 ( 1975$) 599$.

5. Ralph, B., Howe 17, P.R and Page, T.F., Pnys. Stat. Sol (b) (1973) 55641 .

6. Pumphrey, P.H., Gratn Boundary Structure and Properties, Ed. G.A. Chadwick and D.A. Smtth, Academic Press, (1976) 139 .

7. Pond, R.C., smith, D.A., and Clark, W.A.T., J.MiC. $102(1974) 309$.

8. Randle, V., and Ralph, B., J.Mat.Sct (1987) in press.

9. Ralph, B., and Randle, V., Lloyd, J. and ECOD, R.C., Proc $\times 1$ th Inst. Cong. on Electron Microscopy, Kyoto, (1986) 143.

10. Ishida, $Y$ and McLean, M., Phi 7 Mag. 35 (1977) 603 .

11. Marttkatrien, H.O., and Ltridroos, V.K., Acta Met. 31 (1983) 1909.

12. Howe 17, P.R., Fleet, D.E., Welch, P.T. and Ralph, B., Acta Met. 26 (1978) 1499.

13. Bo7 1mann, w., Crystal Defects and Crystal11ne Interfaces, Springer-Verlag, Beritn, (1970).

14. Btshop, G.H. and Chatmers, B., Scripta Met. 2 (1968) 133.

15. Ashby M.F., Spaepen, $F$ and Wtiltams, S., Acta. Met. 26 (1978) 1647. 
15. Vitek, V., Sutton, A.P., Smith, D.A., and Porid, R.C., Grain Boundary Structure and ktrettes, ASM, onio (1980) 115.

17. Balluffi, R.W., and Tan, T.Y., Scripta Met. $6(1972) 1033$

18. Aust, K.T., and Rutter, J.W., Trans. AIME 215 (1959) 820 .

19. Messmer, R.P., and Briant. C.L., Acta Met. $30(1982) 457$.

20. Watanabe, T., Res Mechanica 11 (1984) 47

21. Gordon, $P$ and Vandermeer, R.A., Fiecrystalitsation, Grain Growth arid Textures, Ed. H. Margolin, ASM, Onio, (1965), 205 .

22. Cotteri17, $P$ and Mould, P.R., Recrystallisation and Grain Growth in Meta1s, Surrey University Press, (1976).

23. Randle, V., and Ralph, B. J.Mat.Sct. 21 (1986) 3823.

24. Randle, V., Ralph, B. and Dingley, D.J. submitted to Acta Met.

25. Randie, $V$., and Ralph, B., submitted to J.Mat. Sct.

26. Randle, $V .$, and Ralph, B., Mat.Sci. Tech., in press.

27. Asnoy, M.F., Phit, Mag., 14, (1960), 7757 .

28. Goodnew, P.J., Op.cit. Ref. (16), 155

29. Watanabe, T., arid Masuda, $Y$., J.Jap.Soc. Powder and Powder Met., 29 (1982) 151 .

30. Lim, L.C., and Raj, R., Op.Cit Ref (1), 581 .

31. Grabski, M.W., Op.Cit Ref. (1), 567.

32. Sickafus, K.E., arid sass, 5.L., Acta Met $35(7987) 69$.

Figure 7. Transmission electron micrographs exntbtting cel1 formation near to grain boundaries in deformed Dolycrystals a) aluminium after a stratn of 0.1 (courtesy of I.Barker and $J$. Preston). b) nickel after a strain of 0.8 and a heat treatment which has lead to a partial1y recovered (nere) and partial1y recrystalitsed substructure.
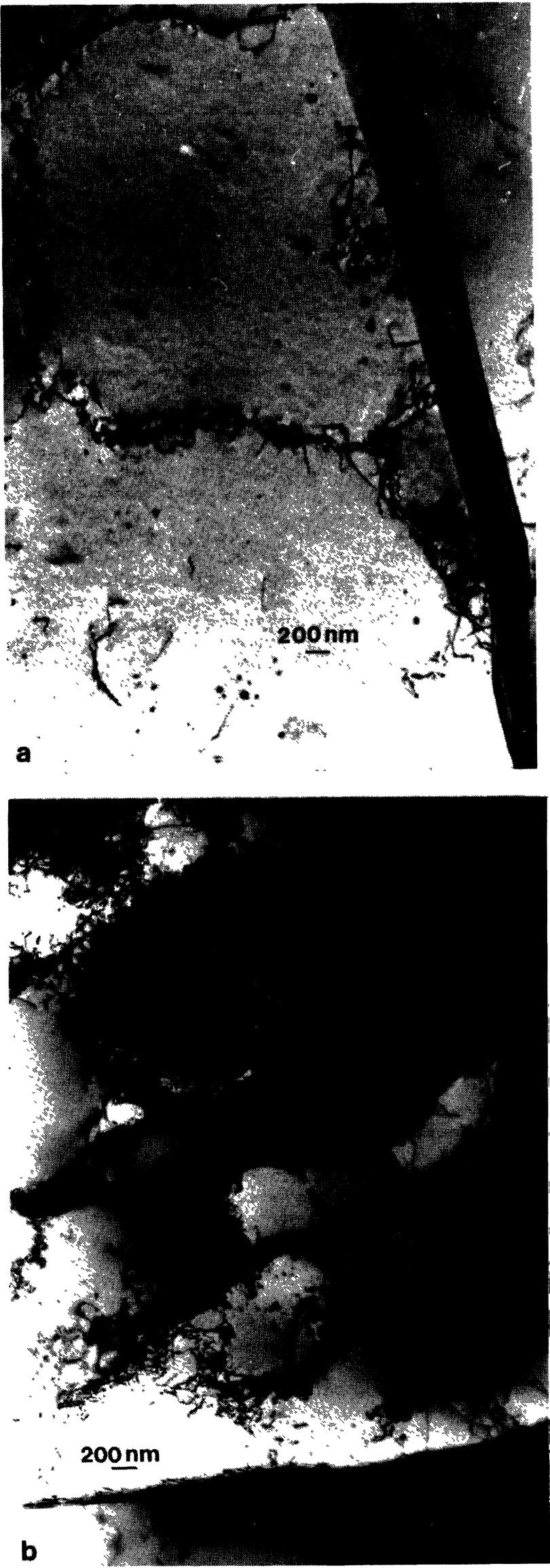